\title{
Hospital Discharge Decisions Concerning Older Patients: Understanding the Underlying Process
}

\author{
Pierre Koskas, Cécile Pons-Peyneau, Mouna Romdhani, Nadège Houenou-Quenum, \\ Sandrine Galleron, and Olivier Drunat \\ Department of Psycho-Geriatrics, Bretonneau Hospital, Assistance Publique-Hôpitaux de Paris, \\ France
}

\begin{abstract}
RÉSUMÉ
L'hospitalisation des personnes âgées s'accompagnent d'un risque de déclin fonctionnel, et d'une grande fréquence de réadmission. Nous avons cherché à comprendre les processus de prise de décisions cliniques qui influencent l'orientation des patients âgés après leur sortie de l'hôpital. Les procédures déterminant l'orientation d'un patient âgé après une hospitalisation en service aigu ne sont pas claires. Nous avons comparé les décisions d'orientation (retour à domicile ou maison de retraite) réalisées par l'équipe avec celles d'un groupe d'experts; les décisions étaient prises de manière indépendante et aveugle. Cent deux (102) patients ont été inclus (âge moyen : $83,13 \pm 6,74)$. Il existe une différence statistiquement significative entre les décisions des experts et de l'équipe ( $\mathrm{p}<.001$; coefficient kappa : 0,468). Les décisions du panel étaient plus étroitement associées à l'isolement $(\mathrm{p}=0,018)$, aux aidants fiables $(\mathrm{p}=0,004)$, aux problèmes sociaux $(\mathrm{p}=0,001)$, et à la présence de comportements perçus comme agressifs $(p=0,001)$. Les deux processus de décision ont pris en compte le refus de soins $(p=0,025$ et 0,016 respectivement) et les problèmes sociaux ( $p=0,001$ et $<0,001$ respectivement). Les modalités de sortie des hôpitaux diffèrent selon les pays, les équipes et le type de patients, mais notre étude suggère la nécessité d'une évaluation plus précise des besoins du patient.
\end{abstract}

\begin{abstract}
We aimed to understand clinical decision-making processes that influence the orientation of older patients after hospital discharge. We compared discharge decisions (i.e., discharge home, or nursing home stay) of the hospital team with those of an expert panel. Both panel and hospital team made their decisions independently. The blind study included 102 patients (mean age: $83.13 \pm 6.74$ ). There is a statistically significant difference between expert and hospital team decisions ( $\mathrm{p}<.001$; kappa coefficient: 0.468). Panel decisions were more closely associated with isolation $(p=.018)$, reliable caregivers $(p=.004)$, social problems $(p=.001)$, and behavioural symptoms perceived as aggressive $(p=.001)$. Both decision processes considered refusal of care $(\mathrm{p}=0,025$ and 0.016 respectively) and social problems $(p=.001$ and $<0.001$ respectively). Discharge planning models differ depending on the country, team and patient's condition. Our study suggests more precise evaluation of patients' needs.
\end{abstract}

Manuscript received: / manuscrit reçu : 07/09/17

Manuscript accepted: / manuscrit accepté : 02/06/18

Mots-clés : vieillissement, sortie de l’hôpital, prise de décision, démence

Keywords: aging, hospital discharge, decision-making, dementia

La correspondance et les demandes de tirés-à-part doivent être adressées à : / Correspondence and requests for offprints should be sent to:

Pierre Koskas, M.D., Neurologist

Memory Center, Bretonneau Hospital

Assistance Publique-Hôpitaux de Paris

23 rue Joseph de Maistre

75018 Paris, France

(pierre.koskas@aphp.fr) 


\section{Background}

Older people are the fastest growing sector of the population. In France, the population over age 65 in 2015 represented 19 per cent of the total (nearly 12 million), with about 1.5 million over the age of 85 (Insee Populations légales 2012 - 75-Paris, n.d.). In recent years, older people have accounted for the largest increase in hospital admissions (Organisation for Economic Co-operation and Development [OECD], n.d.; Office for National Statistics, 2013), with an increasing economic burden on health care systems. In France, data (Agence Technique de l'information sur l'Hospitalisation, n.d.) recorded 12.2 million persons hospitalized in an acute unit in 2016 (184 per 1,000), with 1.5 million older than 80 years of age (402 per $1,000)$. The French National Health Insurance (NHI) is largely controlled by the French state. NHI reimburses patients' outlays on care-related hospitalisations, outpatient services, prescription drugs, and to a lesser extent, dental and vision care (Rodwin, 2003). Unlike other countries such as the United States, the very ill patients are those who will pay the least, because the NHI then assumes the full cost of care.

Hospitalizations are frequently associated with an increased risk of functional decline (Covinsky et al., 2003; Kortebein, Ferrando, Lombeida, Wolfe, \& Evans, 2007) both during hospitalization and following discharge. Several studies emphasise that about 30 per cent of older patients have lost the ability to perform some activities of daily living at hospital discharge in comparison with their pre-illness baseline (Covinsky et al., 2003; McCusker, Kakuma, \& Abrahamowicz, 2002), and the oldest are at high risk of developing new functional deficits during hospitalization (Volpato et al., 2007), which may also precipitate cognitive decline (McCusker et al., 2002). This loss is strongly correlated with higher use of health resources (Covinsky et al., 2003; Hasan, 2001), greater caregiver burden, institutionalization, and death (Cornette et al., 2006; Teno et al., 2000). However, functional decline in older people also occurs frequently before hospitalization, and recovery or decline in the hospital is a complex, dynamic process (Covinsky et al., 2003; Ellis, Whitehead, Robinson, O'Neill, \& Langhorne, 2011).

Readmission of older patients is frequent and poorly understood (Hasan, 2001). In recent years, several studies have sought to identify risk factors for hospital readmissions (Alassaad et al., 2015), institutionalization, or death (Deschodt et al., 2011; McCusker et al., 2002; Mudge, O'Rourke, \& Denaro, 2010). Older people often have coexistent medical, functional, psychological, and social needs (Ellis et al., 2011), requiring assessment on several fronts and involving several disciplines. The goal of comprehensive geriatric assessment
(Ellis et al., 2011) is to identify each problem and to manage it appropriately. Although nutritional assessment remains a priority, nutritional scores such as Mini Nutritional Assessment (MNA) do not support accurate prediction (Dent, Chapman, Howell, Piantadosi, \& Visvanathan, 2014). However, frailty syndromes are a valid predictor of outcomes after acute hospitalization (Dent et al., 2014; Warnier et al., 2016). Several screening tools are in use to predict readmission or functional decline (Cornette et al., 2006; Covinsky et al., 2003; McCusker et al., 2002). Variables include patient demographic factors, medical co-morbidity data, laboratory data, social determinants of health, patient functional status, and prior use of health care services. For example, frequently used scores - Identification of Seniors At Risk (ISAR) (Dendukuri, McCusker, \& Belzile, 2004), Variable Indicative of Placement Risk (VIP), and the Flemish version of the Triage Risk Screening Tool (fTRST) (Braes et al., 2009; Deschodt et al., 2011) - are about equally effective in predicting functional decline and use of health services (Braes et al., 2009) but with a high level of false positives. These scores either fail to provide accurate risk prediction for hospitalized older patients or are too complicated for routine use.

It would be useful, nonetheless, to understand the processes and criteria that underlie decisions of discharge from hospital. To our knowledge, few studies (Ellis et al., 2011; Mudge et al., 2010) have analysed them.

Our main objective was to understand clinical decisionmaking concerning the discharge of older hospital patients. We compared discharge decisions (i.e., discharge home or offer of a nursing home stay) by the hospital team with those of an independent expert panel, and looked at the proportion of patients still at home 3 months after being discharged from hospital. Our second objective was to analyse the main parameters associated with the hospital team's decisions and the panel's decisions.

\section{Method}

Population

This case note review was carried out at the Bretonneau Hospital (Assistance Publique, Paris) during the period between January and June 2016. Bretonneau Hospital was created in 2000 as a resource centre for older patients with dementia or psychiatric conditions in the region (the 9th, 17th, and 18th Paris arrondissements). All hospitalized patients previously living at home were considered in this study. Only patients with a Mini-Mental State Examination (MMSE) score of less than 15 were excluded.

Bretonneau Hospital has had a specific database since 2006 (regulated for data protection purposes by the 
Commission Nationale de l'Informatique et des Libertés, authorization $\mathrm{n}^{\circ} 1858079$ ). Socio-demographic and medical data are systematically collected.

We retained the following items for our study:

(1) Socio-demographic characteristics including age, gender, marital status, household composition, formal and informal caregivers, and years of formal education. We used 7 categories for educational level: 1 for no school, 2 for 10 years of education, 3 for 14 years of education, 4 for 17 years of education, 5 for 18 years of education, 6 for 20 years of education, and 7 for more than 20 years of education (Amieva et al., 2005).

(2) Overall cognitive function was assessed with the MMSE as a screening test in accordance with the French National Alzheimer's Database (Pradier et al., 2014); functional status was assessed using the Instrumental Activities of Daily Living (IADL) score (Law, Barnett, Yau, \& Gray, 2011). If there was already a diagnosis of dementia, we noted it.

(3) Geriatric assessment included the risk of falls, variations in weight (which is a strong predictor of adverse outcome; Soto et al., 2012), asthenia, number of co-morbid conditions, number of treatments, and Framingham score (Amieva et al., 2005). All patients underwent an assessment of their daily living needs using the French "Iso Resource Group" (Groupe Iso Ressources or GIR) scale (Somme \& de Stampa, 2011), which is an overall assessment of social needs in six categories. GIR category 6 is for those who are not dependent on others, and category 1 is for the most dependent.

(4) Psychiatric assessment included the French version of the Neuro-Psychiatric Inventory (NPI; Koskas, HenryFeugeas, Feugeas, Ou, \& Drunat, 2017), psychiatric illness, and personality disorders.

\section{Blind Assessment}

A panel of three experts (a neurologist, a psychiatrist, and a geriatrician) reached consistent decisions on patient hospital discharge (i.e., discharge home or offer of nursing home stay) after studying the patient's data during the last days of the hospitalization for each patient included in the study. These practitioners met once a week to give a consensus opinion for hospital discharge. For this study, we considered that the expert panel constituted the "gold standard" of decisionmaking.

The expert review panel was systemically required, and so both reviews occurred with all patients being discharged. If a patient's MMSE was less than 15, the expert panel did not pursue their assessment.

The study was blinded in that neither the hospital team nor the expert panel saw the other team's decision before making their own. However, this process did not affect the final decision, which always aligned with the recommendation of the hospital staff.

\section{Main Outcomes}

We compared the hospital team decision with the expert panel decision for each patient to determine how closely these two processes corresponded. We analysed the association between the hospital discharge decision (i.e., discharge home or offer of nursing home stay) with the social and medical parameters listed in Tables 1 and 2.

For patients discharged home, a phone interview was carried out 3 months after discharge with either the patient or a designated contact (caregiver or general practitioner) to find out if the patient was still at home. It should be noted that, as the final decision was made by the hospital team, we could not compare the number of patients still at home at 3 months with the panel decision.

\section{Ethics}

This is a retrospective study without clinical or therapeutic intervention that did not require the approval of the ethics committee. Nevertheless, all patients and families were notified of the protocol and signed an agreement form for their participation.

\section{Data Analysis}

Quantitative variables were indicated as mean \pm standard deviation. Qualitative variables were indicated as number and percentage of the total.

We compared the team and panel decisions using chisquare, and determined a kappa coefficient.

For quantitative and qualitative variables, we carried out regression analysis with three models using the expert panel decision, the hospital team decision, and "patients still at home at 3 months" as dependent variables. We retained $p<.05$ for all analysis except for the last regression analysis using 17 comparative variables. Significant levels of $p$ were .003 corrected for multiple comparisons using the Bonferroni correction.

Table 1: Patients' main characteristics $(n=102)$

\begin{tabular}{lc}
\hline Variables & $\boldsymbol{M} \pm \mathbf{S D}$ (max-min) \\
\hline Age & $83.13 \pm 6.74(67-97)$ \\
Female & $81(79 \%)$ \\
Number of co-morbidities & $4.28 \pm 1.98(0-10)$ \\
Number of medications & $5.57 \pm 2.8(0-17)$ \\
Mini-Mental State Examination (0-30) & $20.2 \pm 3.29(15-25)$ \\
Sociocultural level (1-7) & $4.49 \pm 1.76(2-7)$ \\
Instrumental Activities of Daily Living (0-4) & $2.81 \pm 1.37(0-4)$ \\
Activities of Daily Living (0-6) & $3.84 \pm 1.67(0-6)$ \\
Weight (kg) & $61.78 \pm 16.44(32-110)$ \\
Framingham index (0-4) & $1.07 \pm 0.8(0-3)$ \\
\hline
\end{tabular}


Table 2: Patients' social and medical characteristics $(n=102)$

\begin{tabular}{|c|c|c|}
\hline Variables & No. patients (n) & $\%$ \\
\hline \multicolumn{3}{|l|}{ Social Characteristics } \\
\hline Substandard housing & 16 & 15.87 \\
\hline Living alone & 67 & 65.69 \\
\hline Living with spouse & 30 & 29.41 \\
\hline Isolation & 33 & 32.35 \\
\hline Reliable family caregivers & 52 & 50.98 \\
\hline Family support occasionally & 39 & 38.23 \\
\hline Family support frequently & 30 & 29.41 \\
\hline $\begin{array}{l}\text { Legal protection for those lacking mental } \\
\text { capacity }\end{array}$ & 13 & 12.74 \\
\hline $\begin{array}{l}\text { Professional home service less than } 3 \text { days } \\
\text { per week }\end{array}$ & 70 & 68.63 \\
\hline Professional home service 5 days per week & 8 & 7.84 \\
\hline Professional home service 7 days per week & 24 & 23.53 \\
\hline \multicolumn{3}{|l|}{ Medical Characteristics } \\
\hline Dementia & 85 & 83.33 \\
\hline Anosognosia & 45 & 44.12 \\
\hline Risk of falls & 60 & 58.82 \\
\hline Weight loss & 22 & 21.6 \\
\hline Asthenia & 41 & 40.2 \\
\hline Refusal of care & 28 & 27.45 \\
\hline Motor disturbance & 14 & 13.73 \\
\hline Aggression & 16 & 15.69 \\
\hline Agitation & 21 & 20.59 \\
\hline Delusions & 23 & 22.55 \\
\hline Disinhibition & 7 & 6.86 \\
\hline Nighttime behaviour & 17 & 16.67 \\
\hline Depression & 26 & 25.49 \\
\hline Anxiety & 46 & 45.1 \\
\hline \multicolumn{3}{|l|}{ Main Problem during Hospitalization } \\
\hline Social problem & 41 & 40.2 \\
\hline Cognitive problem & 95 & 93.14 \\
\hline Psychiatric problem & 66 & 64.71 \\
\hline Physical problem & 65 & 63.73 \\
\hline
\end{tabular}

\section{Results}

Population

We included 102 patients in our study. It was a community-dwelling geriatric population (mean age 83.13 years \pm 6.74$)$. About 65 per cent were living alone before their hospitalization, and only half had a reliable caregiver. Although 83 per cent had mild or moderate dementia (MMSE $20.2 \pm 3.29$; ADL $3.84 \pm 1.67$ ), about 44 per cent had anosognosia, and about 13 per cent were subject to the French regime of legal protection for those lacking mental capacity. Social problems were present in 40 per cent of cases and substandard housing in 16 per cent. All characteristics are summarized in Tables 1 and 2 .

\section{Correlation of Hospital Team and Expert Panel Decisions}

The expert panel and the hospital team made the same decision for 76 patients (74.5\% of the cases): 24 times opting for admission to a nursing home and 53 times for a return home. There is a statistically significant difference between their decisions $(p<.001)$. The agreement is moderate with a kappa coefficient of 0.468 [0.95 CI: 0.29-0.65] (Table 3).

Of 102 patients, the hospital team decided to discharge 63 patients home. The phone interview carried out 3 months after discharge found 45 patients still at home, 13 persons in nursing homes, and 5 deceased patients. As mentioned above, blind expert decision did not influence final hospital team decision.

\section{Regression Analysis}

For quantitative variables in the two models - namely, "panel's decisions" and "hospital team's decisions" only MMSE ( $p=.017$ ) reached a significant threshold for expert decision (Table 4a).

For qualitative variables, the panel's decisions were associated with isolation $(p=.018)$, reliable caregivers $(p=.004)$, and social problems $(p=.001)$. The "hospital team's decisions" were associated with legal protection for those lacking mental capacity $(p=.045)$ and behavioural symptoms perceived as aggressive $(p=.001)$. We would emphasise the significant association for both decision processes with refusal of care (respectively $p=.025$ and .016) and social problems (respectively $p=.001$ and <.001) (Table 4b).

We explored the model using "patient still at home at 3 months" as the dependent variable $(n=63$ patients; patients not returning home were excluded) with the same parameters. We obtained information for 100 per cent of patients (either from the patient or from the designated contact). Of these 63 patients, $13(32.5 \%)$ were no longer at home when the 3-month telephone survey was carried out. We found that MMSE remained the only variable significantly associated with "at home at 3 months" in the quantitative regression analysis. Only "living alone" ( $p=.037)$ and "isolation" $(p=.038)$ reached a significant threshold in qualitative analysis (Tables $4 \mathrm{a}$ and 4b).

\section{Discussion}

Our main finding was the discrepancy between the hospital team and expert panel decisions for patient hospital discharge. Our analyses showed that different parameters were being used in the decision processes of the hospital team and the panel, but it should be noted that "social problems" and "refusal of care" were common parameters. The association between patients who were still able to remain at home 3 months after discharge and various social parameters, particularly "isolation" and "living alone", is also noteworthy. Although our study focused on a French psychogeriatric 
Table 3: Decision agreement between hospital team and expert-panel hospital team

\begin{tabular}{lccr}
\hline Expert-Panel Proposition & Nursing Home $(\boldsymbol{n}$ decisions) & Discharge Home $(\boldsymbol{n}$ decisions) & No. Patients $(\boldsymbol{n})$ \\
\hline Nursing home & 24 & 10 & 34 \\
Discharge home & 15 & 53 & 68 \\
No. of patients & 39 & 63 & 102 \\
\hline
\end{tabular}

Note. The agreement is moderate with a kappa coefficient of 0.468 [0.95 Cl: $0.29-0.65]$ and $p=4.24 .10^{-6}$ statistically significant difference between their decisions.

unit, we emphasised the similarities between geriatric acute units and psychogeriatric units with a high frequency of persons living with dementia and frailty (Peyneau, Koskas, Romdhani, Houenou-Quenum, \& Drunat, 2016) and also with psychogeriatric units in other countries (Clerencia-Sierra et al., 2015).

We were surprised by the discrepancy between the hospital team and expert panel decisions. Hospital discharge (Bowles, Foust, \& Naylor, 2003) requires careful, comprehensive assessment of patients' needs (Bowles, Naylor, \& Foust, 2002). Hospital teams assessing medical and social needs make empirical decisions based on the practitioners' skills and knowledge. However, there is a wide variation in hospital policies, and/or discharge procedures and planning (Bowles et al., 2003; Mamon et al., 1992). We explain the discrepancy in terms of specific human and environmental factors that provide the empirical knowledge base that discharge decision-makers use in everyday hospital care.

Moreover, interdisciplinary input and especially nurse opinion in planning the patient's home care is a key factor missing from the panel decisions. We found that

Table 4a: Linear regression (a) with expert panel decision as dependent variable $(n=102)$; (b) with hospital team decision as dependent variable $(n=102) ;(c)$ with "at home at 3 months" as dependent variable $(n=63)$

\begin{tabular}{|c|c|c|c|c|c|}
\hline \multicolumn{2}{|c|}{ Explicative Quantitative Variables } & \multirow{2}{*}{$\begin{array}{c}\text { Values } \\
0.018\end{array}$} & \multirow{2}{*}{$\begin{array}{c}\text { Standard Error } \\
0.108\end{array}$} & \multirow{2}{*}{$\begin{array}{c}\boldsymbol{t} \\
0.170\end{array}$} & \multirow{2}{*}{$\frac{\operatorname{Pr}>|+|}{.865}$} \\
\hline & (a) & & & & \\
\hline Age & (b) & -0.112 & 0.110 & -1.014 & .313 \\
\hline \multirow{3}{*}{ Sociocultural level } & (a) & 0.040 & 0.100 & 0.396 & .693 \\
\hline & (b) & 0.094 & 0.136 & 0.696 & .490 \\
\hline & (c) & 0.170 & 0.126 & 1.351 & .182 \\
\hline \multirow[t]{2}{*}{ Framingham index (0-4) } & (b) & 0.092 & 0.117 & 0.780 & .437 \\
\hline & (c) & -0.057 & 0.150 & -0.378 & .707 \\
\hline \multirow{3}{*}{ Weight (kg) } & (a) & -0.177 & 0.116 & -1.530 & .129 \\
\hline & (b) & -0.197 & 0.118 & -1.666 & .099 \\
\hline & (c) & -0.066 & 0.149 & -0.442 & .661 \\
\hline Number of co-morbidities & (a) & -0.047 & 0.110 & -0.430 & .668 \\
\hline \multirow[t]{2}{*}{ No. of medications } & (b) & -0.111 & 0.110 & -1.011 & .315 \\
\hline & (c) & -0.117 & 0.140 & -0.833 & .409 \\
\hline \multirow{3}{*}{ MMSE (0-30) } & (a) & -0.242 & 0.100 & -2.429 & $.017^{*}$ \\
\hline & (b) & 0.053 & 0.102 & 0.604 & .604 \\
\hline & (c) & 0.006 & 0.134 & 0.042 & .966 \\
\hline \multirow{3}{*}{ IADL (0-4) } & (a) & 0.173 & 0.102 & 1.705 & .092 \\
\hline & (b) & 0.152 & 0.104 & 1.460 & .148 \\
\hline & (c) & -0.151 & 0.144 & -1.055 & .296 \\
\hline \multirow{3}{*}{ ADL (0-6) } & (a) & 0.123 & 0.101 & 1.214 & .228 \\
\hline & (b) & -0.077 & 0.104 & -0.744 & .459 \\
\hline & (c) & 0.258 & 0.130 & 1.992 & .051 \\
\hline
\end{tabular}

Note. ADL = Katz Activities of Daily Living; IADL = Lawton Instrumental Activities of Daily Living; MMSE = Mini-Mental State Examination; $\operatorname{Pr}=$ probability.

$* p<.05$. 
Table 4b: Regression analysis (a) with expert panel decision as dependent variable ( $n=102)$; (b) with hospital team decision as dependent variable $(n=102)$; (c) with "at home at 3 months" as dependent variable $(n=63)$

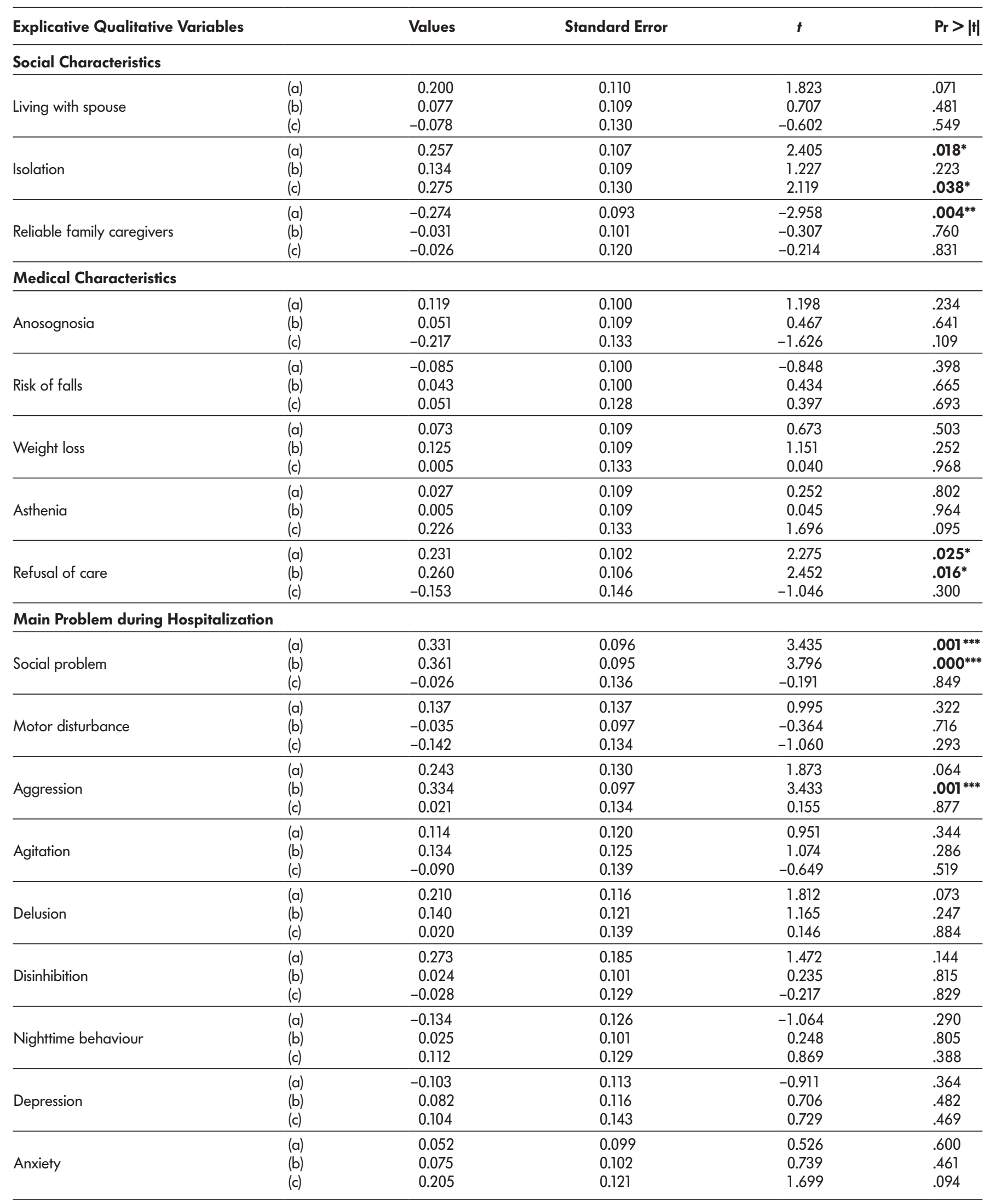

Note. ${ }^{*} p<.05 .{ }^{* *} p<.005 .{ }^{* * *} p$ corrected for multiple comparisons using the Bonferroni's correction $p<0.003$. 
the MMSE score was statistically associated with the expert panel decisions but not with the hospital team decisions. For example, the Hospital Admission Risk Profile (HARP 3) puts the emphasis on a number of independent predictors of functional decline: increasing age, lower admission scores on MMSE and on the Instrumental Activities of Daily Living scale (IADL; Sager et al., 1996), and the Score Hospitalier d'Evaluation $\mathrm{du}$ Risque de Perte d'Autonomie scale (SHERPA; Cornette et al., 2006), which includes five factors: (a) age, (b) impairment in premorbid instrumental ADLs, (c) falls in the year before hospitalization, (d) cognitive impairment, and (e) poor self-rated health. Sensitivity and specificity are low $(67.9 \%$ and $70.8 \%$ respectively). MMSE is a well-known screening tool but with low sensitivity (Roalf et al., 2013) and is potentially misleading. Similarly, the IADL and Katz ADL scales are not sufficiently sensitive (Koskas et al., 2014) and were not associated with decision-making by the hospital team or the expert panel. Everyday observation of the patient by the team is certainly more pertinent.

We tried to identify the patterns of information gathering used by health professionals in making discharge decisions. Social problems (isolation, lack of reliable caregivers, and refusal of care) were associated with both the hospital team and panel hospital discharge decisions in our study. It is generally agreed that these factors are important when reaching appropriate discharge decisions (Bowles et al., 2003; Naylor et al., 1994). Several indices that focus on hospital discharge (Cornette et al., 2006; Dendukuri et al., 2004; Deschodt et al., 2011; Donze et al., 2013; Prescott, Soeken, \& Griggs, 1995; Teno et al., 2000) seem less pertinent for social assessment. We think that hospital discharge is better characterized as a continuous process instead of an isolated event (Bowles et al., 2003; Mamon et al., 1992; Naylor et al., 1994; Nyweide et al., 2013). Continuity of hospital and ambulatory care reduced the rate of hospitalization (Amjad, Carmichael, Austin, Chang, \& Bynum, 2016; Nyweide et al., 2013;). Although a hospital team usually assesses the patient's clinical characteristics when making these decisions, they also have to coordinate follow-up services and home care. Anticipating future needs will help them make appropriate decisions (Amjad et al., 2016). In France, a geriatric network (Somme, 2014) has been in place for several years. However, this integrated care structure is faced with problems due in particular to the difficulty of coordinating the various facilities and their cost (Pimouguet, Lavaud, Dartigues, \& Helmer, 2010).

Our study features telephone follow-up of the patient or a referral at 3 months. Other studies have been carried out with shorter follow-up (Bowles et al., 2002; Naylor et al., 1994). It seems likely that patients who are readmitted to hospital within two weeks of discharge had often been discharged before their treatment had had its full effect, to some extent because shorter hospital stays are an objective of public services, with the goal of reducing insurance costs.

Our study found that a high percentage of patients $(32.5 \%)$ were still able to remain at home 3 months after discharge from hospitalization. The literature (Hasan, 2001) reveals a wide range of possible reasons for hospital readmission. Poor patient compliance and living alone (Williams \& Fitton, 1988) have previously been described, as in our study. These problems are a major obstacle to the establishment of home care and follow-up at home. Studies have shown that aftercare services are often difficult to implement in these cases. Although the French national Alzheimer's Plan (Rapport d'évaluation du -2012) created several specialized bodies and facilities to reinforce home care, poor patient compliance or lack of a reliable caregiver remain major obstacles. Our study highlighted that a patient's needs could not be met without a wellorganized post-discharge referral.

Some criteria (anosognosia, dementia, and frailty criteria such as asthenia and weight loss) were not statistically associated either with the hospital team or expert panel decisions, or with patients remaining at home after 3 months. We explain these findings by the effectiveness of the hospital team in assessing and solving medical problems. Paradoxically in our study, behavioural criteria were not a factor in decisions made by the expert panel or by the hospital teams, although they are generally associated with a greater risk of institutionalization (Afram et al., 2014; Luppa, Luck, Brähler, König, \& Riedel-Heller, 2008). We think that the specialization of the psychogeriatric unit made it possible to ensure better support for behavioural symptoms. "Aggression" was the only behavioral factor associated with the team's decision in favour of a nursing home.

This study has several weaknesses. Our work was limited to one hospital, and the sample was small. The findings may differ in hospitals in other locations, discharge planning models, patients, or staff. Our findings may not be broadly generalizable over time or place since discharge policies vary in different settings and can change over time. The lack of feedback from the expert panel to the clinical staff is a limitation of our study.

We held meetings throughout our work with the various teams, but this was done informally. Also, we cannot explain in our work the factors of agreement and disagreement of teams with the results found. However, our findings are based on two different models of decision, evaluated blindly in our protocol, and the study focused on hospitalized older adults. 
Although our study suggests the need for improved methods to support clinical decision-making, we note that the clinical staff generally acquires considerable information from direct observations and nonquantifiable assessments. Additionally, clinical staff also need to negotiate with patients and families or institutions, which would have influenced decision-making.

\section{References}

Afram, B., Stephan, A., Verbeek, H., Bleijlevens, M. H. C., Suhonen, R., Sutcliffe, C., \& RightTimePlaceCare Consortium. (2014). Reasons for institutionalization of people with dementia: Informal caregiver reports from 8 European countries. Journal of the American Medical Directors Association, 15(2), 108-116. https://doi.org/10.1016/j. jamda.2013.09.012

Agence Technique de l'information sur l'Hospitalisation. (n.d.) Accès aux bases PMSI | Publication ATIH [Access to PMSI databases]. Lyon, FRA: Author. Retrieved from http:/ / www.atih.sante.fr/bases-de-donnees/commandede-bases

Alassaad, A., Melhus, H., Hammarlund-Udenaes, M., Bertilsson, M., Gillespie, U., \& Sundström, J. (2015). A tool for prediction of risk of rehospitalisation and mortality in the hospitalised elderly: Secondary analysis of clinical trial data. BMJ Open, 5(2), e007259. https:/ / doi.org/10.1136/bmjopen-2014-007259

Amieva, H., Jacqmin-Gadda, H., Orgogozo, J. M., Le Carret, N., Helmer, C., Letenneur, L., ... Dartigues, J. F. (2005). The 9 year cognitive decline before dementia of the Alzheimer type: A prospective population-based study. Brain, 128(5), 1093-1101.

Amjad, H., Carmichael, D., Austin, A. M., Chang, C.-H., \& Bynum, J. P. W. (2016). Continuity of care and health care utilization in older adults with dementia in fee-for-service Medicare. JAMA Internal Medicine, 176(9), 1371-1378. https:/ /doi.org/10.1001/jamainternmed.2016.3553

Bowles, K. H., Foust, J. B., \& Naylor, M. D. (2003). Hospital discharge referral decision making: A multidisciplinary perspective. Applied Nursing Research, 16(3), 134-143. https:/ /doi.org/10.1016/S0897-1897(03)00048-X

Bowles, K. H., Naylor, M. D., \& Foust, J. B. (2002). Patient characteristics at hospital discharge and a comparison of home care referral decisions. Journal of the American Geriatrics Society, 50(2), 336-342. https:/ /doi.org/10.1046/ j.1532-5415.2002.50067.x

Braes, T., Flamaing, J., Sterckx, W., Lipkens, P., Sabbe, M., Rooij, S. E., \& Milisen, K. (2009). Predicting the risk of functional decline in older patients admitted to the hospital: A comparison of three screening instruments. Age and Ageing, 38(5), 600-603. https:/ / doi.org/10.1093/ageing/afp097

Clerencia-Sierra, M., Calderón-Larrañaga, A., Martínez-Velilla, N., Vergara-Mitxeltorena, I., Aldaz-Herce, P., PobladorPlou, B., ... Prados-Torres, A. (2015). Multimorbidity patterns in hospitalized older patients: Associations among chronic diseases and geriatric syndromes. PloS One, 10(7), e0132909. https://doi.org/10.1371/journal.pone.0132909

Cornette, P., Swine, C., Malhomme, B., Gillet, J.-B., Meert, P., \& D'Hoore, W. (2006). Early evaluation of the risk of functional decline following hospitalization of older patients: Development of a predictive tool. European Journal of Public Health, 16(2), 203-208. https:/ / doi.org/10.1093/ eurpub/cki054

Covinsky, K. E., Palmer, R. M., Fortinsky, R. H., Counsell, S. R., Stewart, A. L., Kresevic, D., ... Landefeld, C. S. (2003). Loss of independence in activities of daily living in older adults hospitalized with medical illnesses: Increased vulnerability with age. Journal of the American Geriatrics Society, 51(4), 451-458. https://doi.org/10.1046/j.15325415.2003.51152.x

Dendukuri, N., McCusker, J., \& Belzile, E. (2004). The identification of seniors at risk screening tool: Further evidence of concurrent and predictive validity. Journal of the American Geriatrics Society, 52(2), 290-296.

Dent, E., Chapman, I., Howell, S., Piantadosi, C., \& Visvanathan, R. (2014). Frailty and functional decline indices predict poor outcomes in hospitalised older people. Age and Ageing, 43(4), 477-484. https://doi.org/10.1093/ ageing/aft181

Deschodt, M., Wellens, N. I. H., Braes, T., De Vuyst, A., Boonen, S., Flamaing, J., ... Milisen, K. (2011). Prediction of functional decline in older hospitalized patients: A comparative multicenter study of three screening tools. Aging Clinical and Experimental Research, 23(5-6), 421-426.

Ellis, G., Whitehead, M. A., Robinson, D., O'Neill, D., \& Langhorne, P. (2011). Comprehensive geriatric assessment for older adults admitted to hospital: Meta-analysis of randomised controlled trials. BMJ: British Medical Journal, 343: d6553. https://doi.org/10.1136/bmj.d6553

Hasan, M. (2001). Readmission of patients to hospital: Still ill defined and poorly understood. International Journal for Quality in Health Care, 13(3), 177-179. https: / / doi.org / 10.1093/intqhc/13.3.177

Insee - Institut national de la statistique et des études économiques [National Institute of Statistics and Economic Studies]. (2015). Populations légales 2012-75-Paris [Legal populations 2012]. (2015). Retrieved from http://www. insee.fr/fr/ppp/bases-de-donnees / recensement / populations-legales/departement.asp?dep=75\#pop_arm

Kortebein, P., Ferrando, A., Lombeida, J., Wolfe, R., \& Evans, W. J. (2007). Effect of 10 days of bed rest on skeletal muscle in healthy older adults. JAMA, 297(16), 1772-1774. https: / / doi.org/10.1001/jama.297.16.1772-b

Koskas, P., Henry-Feugeas, M. C., Feugeas, J. P., Ou, P., \& Drunat, O. (2017). Factors of rapid cognitive decline in late onset Alzheimer's disease. Current Aging Science, 10(2), 129-135. 
Koskas, P., Henry-Feugeas, M. C., Feugeas, J. P., Poissonnet, A., Pons-Peyneau, C., Wolmark, Y., \& Drunat, O. (2014). The Lawton Instrumental Activities Daily Living/ Activities Daily Living Scales: A sensitive test to Alzheimer disease in community-dwelling elderly people? Journal of Geriatric Psychiatry and Neurology, 27(2), 85-93. https:/ /doi. org/10.1177/0891988714522694

Law, L. L. F., Barnett, F., Yau, M. K., \& Gray, M. A. (2011). Measures of everyday competence in older adults with cognitive impairment: A systematic review. Age and Ageing, 41(1), 9-16. https:/ / doi.org/10.1093/ageing/afr104

Luppa, M., Luck, T., Brähler, E., König, H.-H., \& RiedelHeller, S. G. (2008). Prediction of institutionalisation in dementia. A systematic review. Dementia and Geriatric Cognitive Disorders, 26(1), 65-78. https://doi.org/10.1159/ 000144027

Mamon, J., Steinwachs, D. M., Fahey, M., Bone, L. R., Oktay, J., \& Klein, L. (1992). Impact of hospital discharge planning on meeting patient needs after returning home. Health Services Research, 27(2), 155-175.

McCusker, J., Kakuma, R., \& Abrahamowicz, M. (2002). Predictors of functional decline in hospitalized elderly patients: A systematic review. The Journals of Gerontology. Series A, Biological Sciences and Medical Sciences, 57(9), M569-577.

Mudge, A. M., O’Rourke, P., \& Denaro, C. P. (2010). Timing and risk factors for functional changes associated with medical hospitalization in older patients. The Journals of Gerontology. Series A, Biological Sciences and Medical Sciences, 65(8), 866-872. https://doi.org/10.1093/gerona/ glq069

Naylor, M., Brooten, D., Jones, R., Lavizzo-Mourey, R., Mezey, M., \& Pauly, M. (1994). Comprehensive discharge planning for the hospitalized elderly. A randomized clinical trial. Annals of Internal Medicine, 120(12), 999-1006.

Nyweide, D. J., Anthony, D. L., Bynum, J. P. W., Strawderman, R. L., Weeks, W. B., Casalino, L. P., \& Fisher, E. S. (2013). Continuity of care and the risk of preventable hospitalization in older adults. JAMA Internal Medicine, 173(20), 18791885. https:/ / doi.org/10.1001/jamainternmed.2013.10059

Office for National Statistics. (2013). What does the 2011 Census tell us about older people. Newport, GBR: Author. Retrieved from http://www.ons.gov.uk/peoplepopulationandcommunity / birthsdeathsandmarriages / ageing/articles/whatdoesthe2011censustellusaboutolderpeople/2013-09-06

Organisation for Economic Co-operation and Development (OECD). (n.d.) Social Expenditure - Aggregated data. Paris, FRA: Author. Retrieved from http://stats.oecd.org/ Index.aspx?datasetcode=SOCX_AGG

Peyneau, C., Koskas, P., Romdhani, M., Houenou-Quenum, N., \& Drunat, O. (2016). Typologie psychiatrique de la personne âgée avec ou sans démence dans un hôpital de gériatrie. Santé Publique, 28(1), 71-75.
Pimouguet, C., Lavaud, T., Dartigues, J. F., \& Helmer, C. (2010). Dementia case management effectiveness on health care costs and resource utilization: A systematic review of randomized controlled trials. The Journal of Nutrition, Health \& Aging, 14(8), 669-676. https://doi. org/10.1007/s12603-010-0314-4

Pradier, C., Sakarovitch, C., Le Duff, F., Layese, R., Metelkina, A., Anthony, S., ... Robert, P. (2014). The Mini Mental State Examination at the time of Alzheimer's disease and related disorders diagnosis, according to age, education, gender and place of residence: A cross-sectional study among the French National Alzheimer database. PloS One, 9(8), e103630. https://doi.org/10.1371/journal. pone. 0103630

Prescott, P. A., Soeken, K. L., \& Griggs, M. (1995). Identification and referral of hospitalized patients in need of home care. Research in Nursing \& Health, 18(2), 85-95.

Roalf, D. R., Moberg, P. J., Xie, S. X., Wolk, D. A., Moelter, S. T., \& Arnold, S. E. (2013). Comparative accuracies of two common screening instruments for classification of Alzheimer's disease, mild cognitive impairment, and healthy aging. Alzheimer's \& Dementia: The Journal of the Alzheimer's Association, 9(5), 529-537. https://doi. org/10.1016/j.jalz.2012.10.001

Rodwin, V. G. (2003). The health care system under French National Health Insurance: Lessons for health reform in the United States. American Journal of Public Health, 93(1), 31-37.

Sager, M. A., Rudberg, M. A., Jalaluddin, M., Franke, T., Inouye, S. K., Landefeld, C. S., ... Winograd, C. H. (1996). Hospital admission risk profile (HARP): Identifying older patients at risk for functional decline following acute medical illness and hospitalization. Journal of the American Geriatrics Society, 44(3), 251-257.

Somme, D. (2014). Integrated care in France: Dream or reality? [Editorial]. International Journal of Integrated Care, 14(1), e053. https://www.ijic.org/article/10.5334/ijic.1540/

Somme, D., \& de Stampa, M. (2011). Ten years of integrated care for the older in France. International Journal of Integrated Care, 11(Special 10th Anniversary Edition), e141. Retrieved from http://www.ncbi.nlm.nih.gov/pmc/ articles/PMC3284287/

Soto, M. E., Secher, M., Gillette-Guyonnet, S., Abellan van Kan, G., Andrieu, S., Nourhashemi, F., ... Vellas, B. (2012). Weight loss and rapid cognitive decline in communitydwelling patients with Alzheimer's disease. Journal of Alzheimer's Disease: JAD, 28(3), 647-654. https://doi. org/10.3233/JAD-2011-110713

Teno, J. M., Harrell, F. E., Knaus, W., Phillips, R. S., Wu, A. W., Connors, A., ... Lynn, J. (2000). Prediction of survival for older hospitalized patients: The HELP survival model. Hospitalized elderly longitudinal project. Journal of the American Geriatrics Society, 48(5 Suppl), S16-24.

Volpato, S., Onder, G., Cavalieri, M., Guerra, G., Sioulis, F., Maraldi, C., ... Italian Group of Pharmacoepidemiology in 
the Elderly Study (GIFA). (2007). Characteristics of nondisabled older patients developing new disability associated with medical illnesses and hospitalization. Journal of General Internal Medicine, 22(5), 668-674. https:/ / doi. org/10.1007/s11606-007-0152-1

Warnier, R. M. J., van Rossum, E., van Velthuijsen, E., Mulder, W. J., Schols, J. M. G. A., \& Kempen, G. I. J. M. (2016).
Validity, reliability and feasibility of tools to identify frail older patients in inpatient hospital care: A systematic review. The Journal of Nutrition, Health \& Aging, 20(2), 218-230. https:/ / doi.org/10.1007/s12603-015-0567-z

Williams, E. I., \& Fitton, F. (1988). Factors affecting early unplanned readmission of elderly patients to hospital. BMJ (Clinical Research Ed.), 297(6651), 784-787. 